Marquette University

e-Publications@Marquette

Spring 2009

\title{
The Nutrition Elite: Do Only the Highest Levels of Caloric Knowledge, Obesity Knowledge, and Motivation Matter in Processing Nutrition Ad Claims and Disclosures?
}

J. Craig Andrews

Marquette University, craig.andrews@marquette.edu

Richard G. Netemeyer

University of Virginia - Main Campus

Scot Burton

University of Arkansas - Main Campus

Follow this and additional works at: https://epublications.marquette.edu/market_fac

Part of the Marketing Commons

\section{Recommended Citation}

Andrews, J. Craig; Netemeyer, Richard G.; and Burton, Scot, "The Nutrition Elite: Do Only the Highest Levels of Caloric Knowledge, Obesity Knowledge, and Motivation Matter in Processing Nutrition Ad Claims and Disclosures?" (2009). Marketing Faculty Research and Publications. 31.

https://epublications.marquette.edu/market_fac/31 


\title{
The Nutrition Elite: Do Only the Highest Levels of Caloric Knowledge, Obesity Knowledge, and Motivation Matter in Processing Nutrition Ad Claims and Disclosures?
}

\author{
J. Craig Andrews, Richard G. Netemeyer, and Scot Burton
}

\begin{abstract}
This study examines the role of the highest levels of caloric knowledge, obesity consequences knowledge, and motivation to search for nutrition information in the processing of relative nutrient content claims in advertisements, such as "half the calories" or "half the fat," for products relatively high in total calorie levels. After controlling for the impact of demographics, dietary habits, body mass index, relative ad claims and disclosures, perceived weight gain risk, and other variables, the authors find curvilinear (quadratic) effects for caloric knowledge, obesity consequences knowledge, and motivation to search for nutrition information on intent to buy an advertised, high-calorie snack bar. This suggests a strengthening of the negative relationship for intent for consumers at the highest levels of caloric knowledge, obesity consequences knowledge, and motivation (i.e., the "nutrition elite"). The authors offer public policy implications, including whether achieving such exceedingly high levels of nutrition knowledge and motivation is realistic for the general public in light of other policy alternatives, such as market-based solutions (e.g., reducing serving sizes, standardized front-ofpackage icons).
\end{abstract}

Keywords: nutrition, advertising, obesity, disclosures, knowledge

$\mathbf{F}$ or many consumers, being overweight is a daily battle with serious long-term consequences. Each year, approximately $25 \%$ of people in the United States are on a diet, spending approximately $\$ 35$ billion per year on weight loss products (Federal Trade Commission [FTC] 2002). Yet the harsh reality is that for those who try, many are unsuccessful in achieving meaningful weight loss, even after repeated attempts. As a result, obesity has increased at an alarming rate over the last 20 years, and this trend is likely to continue (Centers for Disease Control and Prevention [CDC] 2008). Currently, 67\% of all adults in the

J. Craig Andrews is Professor and Charles H. Kellstadt Chair in Marketing, Department of Marketing, Marquette University (e-mail: craig.andrews@marquette.edu). Richard G. Netemeyer is Ralph A. Beeton Professor of Free Enterprise, McIntyre School of Commerce, University of Virginia (e-mail: rgn3p@virginia.edu). Scot Burton is Professor and Wal-Mart Chair in Marketing, Sam M. Walton College of Business, Department of Marketing and Logistics, University of Arkansas (e-mail: sburton@walton.uark.edu). The authors gratefully acknowledge the support of the Kellstadt Foundation, which provided funding for the data collection for this project. They also appreciate the help of Jack Kloc of MarketVision Research in the data collection process. The authors also acknowledge the assistance of Nicholas Beyer (MBA, Marquette University) in the construction of the ad stimuli for the research project. Finally, they thank the anonymous JPP\&M reviewers and the associate editor for their helpful comments on previous drafts of this article.
United States are overweight (body mass index [BMI] > $25)$, and $33 \%$ are obese (BMI > 30). It is estimated that by $2015,75 \%$ of U.S. adults will be overweight, and $41 \%$ will be obese (Wang and Beydoun 2007). When adjusted for age and smoking factors, obesity is associated with approximately 112,000 deaths each year over normal weight categories (Flegal et al. 2005), and it has been linked to increased risk of type 2 diabetes, coronary heart disease, high blood pressure, arthritis, and several types of cancer (CDC 2008).

Consumers attempting to manage their weight face challenges every day in the form of "cues to consume" and diet misperceptions (National Institutes of Health 2006). For example, habitual eating of foods labeled as "low fat" is found to be related to more favorable impressions of serving sizes, higher-calorie side items, decreased consumer guilt, and overconsumption (Wansink and Chandon 2006a). In nutrition marketing, such cues are prevalent and come in the form of nutrient claims and visuals in packaging and advertisements, point-of-sale displays, sponsorships, and other marketing communications. Moreover, the food industry is facing criticism for promoting unhealthy food choices to children through such communications (FTC 2007; Jacobson 2006; Moore 2007).

In general, consumer research addressing the obesity issue has proceeded along two lines: Either it has examined the role of external information (e.g., nutrition labeling, claims and disclosures in advertisements), or it has investigated the internal characteristics of consumers (e.g., knowl-

Journal of Public Policy \& Marketing Vol. 28 (1) Spring 2009, 41-55 
edge about health, nutrition, and motivation) (Moorman 1990). In the case of external information, two prominent ways that consumers obtain nutrition information include (1) Nutrition Facts panels and nutrient content and health claims on packages and (2) nutrition claims and related information from advertising. Yet such external information in the form of nutrition claims can sometimes lead to less-than-optimal consumer decision making. For example, consumers may overgeneralize certain nutrient content claims ("no cholesterol") to low levels of other nutrients ("low in fat") (Andrews, Netemeyer, and Burton 1998). Such "halo effects," in which consumers rate the product as healthier on attributes not explicitly mentioned in the claim, have also been found in the case of health claims on packages (Roe, Levy, and Derby 1999) and can actually lead to increased consumption for overweight consumers (Wansink and Chandon 2006a). Conversely, external information in the form of Nutrition Facts panels (Howlett, Burton, and Kozup 2008; Moorman 1996) and nutrition disclosures (Andrews, Netemeyer, and Burton 1998) has been found to be effective for consumers in reducing misperceptions, enhancing comprehension, and forming accurate beliefs and intentions.

Although research examining external information has greatly enhanced the understanding of consumer reactions to nutrition ad claims and disclosures, work on internal characteristics (e.g., objective nutrition knowledge, motivation to search for information) can offer potentially greater insight into the conditions under which such external information operates (cf. Andrews, Burton, and Netemeyer 2000; Levy, Fein, and Stephenson 1993; Moorman 1990; Wansink 2005). In general, motivation and knowledge serve as key elements that lead to enhanced elaboration of message arguments (Chaiken 1980; Petty and Cacioppo 1986). More specifically, the moderating impact of consumer nutrition motivation, nutrition knowledge, and education on the effects of both nutrition claims and Nutrition Facts panel information has been successfully demonstrated in several studies (e.g., Andrews, Burton, and Netemeyer 2000; Howlett, Burton, and Kozup 2008; Keller et al. 1997; Mitra et al. 1999; Moorman 1990).

However, the traditional approach to the study of how consumer knowledge and motivation affect processing of advertising and other persuasive information has relied on simple, high-low median splits or the experimental manipulation of such factors. Such an approach may potentially obscure the levels at which specific outcomes may or may not be occurring, especially at the highest or lowest levels of such factors. For example, the results in an experiment might show that a high level of knowledge (based on a dichotomous median split) leads to a more favorable effect on an outcome variable than a low knowledge level. However, in reality, responses from the highest levels of this knowledge variable may be needed to produce the desired effect on the outcome, and this may not be evident when a median split is used. From a policy perspective, a major issue is the degree or upper limit to which consumer knowledge and motivation can actually be improved to make a substantial impact. Thus, this study focuses on potential quadratic (curvilinear) effects of different types of knowledge and motivation on consumer decision making, while controlling for the effects of potentially misleading ad claims and corrective disclosures (as external information).

\section{Background and Hypotheses}

\section{External Information: Ad Claims and Disclosures}

Although the primary purpose of this research is to address possible quadratic effects of internal consumer characteristics, these effects are examined in the context of nutrition ad claims (i.e., about reduced calorie and fat levels) and ad disclosures. Thus, we offer a brief summary of prior research on ad claim and disclosure effects, followed by a review of internal characteristics and the conceptual rationale for quadratic effects.

\section{Ad Claims Effects}

Consumer generalizations and inferences from nutrition and health claims are prevalent and can result from positivity biases and "health halo" effects (Andrews, Netemeyer, and Burton 1998; Roe, Levy, and Derby 1999). The mere presence of a low-fat claim has been shown to lead to underestimation of calories and greater consumption (Wansink and Chandon 2006a). In addition, confusion between low-fat claims and low-calorie claims is common among consumers (National Institutes of Health 2006; Wansink and Chandon 2006a). In this article, we first examine "health halos" from ad claims ("half the calories" and "half the fat") in which consumers may form misleading product perceptions because of nutrition information not mentioned in the advertisement. Thus, it is likely that consumers will make "health halo" inferences from reduced-fat and -calorie claims (e.g., "It's healthy," "It's low in fat/calories"), which should result in a negative relationship between ad claims and a key belief variable_namely, perceived weight gain risk. ${ }^{1}$

\section{Ad Disclosure Effects}

The FTC has advocated the use of disclosures to prevent misleading impressions from important omissions in advertising, as long as such disclosures are clearly and conspicuously displayed (FTC 1994; Hoy and Andrews 2004). Research has shown that evaluative disclosures (e.g., characterizing the per-serving level of the nutrient to be "high," as determined by the Food and Drug Administration [FDA]) can be effective in reducing misperceptions and inaccurate generalizations from nutrition claims (e.g., "no cholesterol" and " $1 / 3$ less salt") when related nutrients are at high levels (see Andrews, Burton, and Netemeyer 2000; Andrews, Netemeyer, and Burton 1998). Though for a different product category and disclosed nutrient (i.e., calories), exposure to ad disclosures depicting the actual level

\footnotetext{
1 Our focal dependent variable is intent to buy the advertised snack bar. However, we also measure perceived weight gain risk as a control variable for the prediction of intent and to help establish that study respondents were using "health halo" processing. We anticipate main effects of the ad claims and disclosures on perceived weight gain risk and address these effects in our results. However, given general support in the previously mentioned literature and our focus on the quadratic effects of nutrition knowledge and motivation, we do not offer explicit hypotheses regarding these anticipated effects.
} 
of calories and the evaluation of this level (as high) should be positively related to the perceived weight gain risk of consuming the advertised product.

\section{Internal Characteristics: Nutrition Knowledge and Motivation}

\section{Nutrition Knowledge Types and Effects}

Topic-relevant knowledge represents a key variable that affects a person's ability to process and elaborate on message-relevant arguments in advertisements (Batra and Ray 1986; Chaiken 1980; Petty and Cacioppo 1986). Unfortunately, general consumer nutrition knowledge has been characterized as "poor," and the effects of knowledge on weight management are not as strong as desired (FDA 2004; Levy, Fein, and Stephenson 1993). For example, Brucks, Mitchell, and Staelin (1984) find that though consumers use nutritional information in early stages of information processing (e.g., attention, some recall), they engage in little subsequent processing of the information. Recent research also suggests that general knowledge measures of health and nutrition often have little impact on consumer dietary choices (Wansink and Chandon 2006a).

What might explain the equivocal effects of general knowledge measures of nutrition? A partial answer may lie in the need for some studies to consider the different types of knowledge a consumer has acquired. For example, prior work has examined the effects of subjective nutrition knowledge (Moorman et al. 2004); objective nutrition knowledge (Andrews, Netemeyer, and Burton 1998); and diet and disease knowledge, nutrition label knowledge, and general diet knowledge (cf. Moorman 1996, p. 42; Moorman and Matulich 1993, p. 222). In contrast to more general knowledge measures, the current research extends these findings by focusing specifically on caloric and obesity consequences knowledge, as well as on the quadratic effects from these objective knowledge measures. As a basis for the development of our measures, Wansink (2005) suggests two tiers of objective consumer knowledge: (1) caloric and nutrient knowledge that addresses nutrition attributes, such as the calorie content and fat levels of foods, and (2) knowledge that is related to the health consequences of consumption and obesity. These two tiers of knowledge are distinct and may have separate effects on dietary beliefs and choices (Wansink and Cheney 2005). Furthermore, the distinction between attribute knowledge and consequences knowledge is an important one that also serves as the basis for advertising strategy found in work on means-end chaining (Reynolds and Olson 2001). Thus, in this study, we measure two tiers of knowledge: (1) objective calorie/fat knowledge with a focus primarily on caloric content (hereinafter, we refer to this as "caloric knowledge") and (2) objective knowledge of the negative health consequences of obesity (hereinafter, we refer to this as "obesity consequences knowledge").

\section{Nutrition Knowledge Quadratics}

To the best of our knowledge, all consumer research focusing on the effects of nutrition knowledge on beliefs and/or behaviors has examined simple dichotomous or linear relations. Yet recent consumer research in a wide variety of domains suggests that concentrating on very high (or low) levels of a predictor variable-potential curvilinear or quadratic effects - can offer more diagnostic information to both consumers and the firms that market to them (Agustin and Singh 2005; Anderson 1998). In the case of nutrition knowledge, such effects may show that the favorable influence of educational efforts is limited to consumers at the uppermost levels of knowledge. Furthermore, such curvilinear effects are often theoretically insightful because they offer a new perspective on the bivariate relationships traditionally thought of as only linear (Ganzach 1997; MacCallum and Mar 1995).

We anticipate potential quadratic (curvilinear) effects related to knowledge for the following reasons: First, consumer processing research suggests that highly knowledgeable consumers make the best use of information, leading to improved decision making (Alba and Hutchinson 1987; Brucks, Mitchell, and Staelin 1984), and this may be more pronounced at the highest levels. In a recent study, Chandon and Wansink (2007b) found that though professional dieticians (with greater knowledge) underestimated mean calorie content of a fast-food meal, their underestimation was much less pronounced than that of consumers from the general public. Second, theories of dual information processing posit that behaviors may be more strongly affected at the highest levels of knowledge (Chaiken 1980; Petty and Cacioppo 1986) and that these effects may be disproportional to the effects at lower or moderate levels (nonlinear). Indeed, in examining warning labels as a context, Zuckerman and Chaiken (1998, p. 622) state that "prototypical systematic processing refers to the upper end of a data seeking/analysis/integration continuum." This suggests that at the highest levels of objective knowledge, the effects on intent should be most pronounced (i.e., a quadratic or a negative asymmetric effect).

Thus, we examine the following question: Do consumers at the highest levels of caloric and obesity consequences knowledge form stronger (more negative) intentions to buy the brand than consumers at low or more moderate to high levels? On the basis of the previously discussed rationale, we hypothesize negative quadratic effects (i.e., nonlinear downward-sloping curves or "negative asymmetric effects"; see Anderson 1998; Cohen et al. 2003) for caloric knowledge and obesity consequences knowledge on intent to buy the brand. ${ }^{2}$

$\mathrm{H}_{1}$ : There is a negative quadratic relationship between caloric knowledge and intent to buy the brand. At the highest levels of caloric knowledge, the effect on consumers' intent to buy the brand is a downward-sloping curve-a negative asymmetric effect-which is in contrast to consumers with low or moderate knowledge levels.

$\mathrm{H}_{2}$ : There is a negative quadratic relationship between obesity consequences knowledge and intent to buy the brand. At the highest levels of obesity consequences knowledge, the effect on consumers' intent to buy the brand is a

\footnotetext{
2 We use a conservative hierarchical test to examine the proposed quadratic effects by entering several control variables (including a subjective nutrition knowledge measure and perceived weight gain risk), as well as effects of objective knowledge types and motivation before examining the effects of the quadratic terms.
} 
downward-sloping curve-a negative asymmetric effectwhich is in contrast to consumers with low or moderate knowledge levels.

\section{Motivation to Search for Nutrition Information}

As is the case with knowledge, motivation to search for information represents a key variable affecting the elaboration or systematic processing of a message (Chaiken 1980; Petty and Cacioppo 1986). In turn, this can positively affect consumer perceptions, attitudes, and intent with cogent or credible message arguments (Andrews, Durvasula, and Akhter 1990). As applied to nutrition, the findings indicate that more motivated consumers tend to acquire and use nutrition information to a greater extent than those not as motivated (Moorman 1990, 1996). Moreover, health motivation is found to positively influence consumers' preventive health behaviors (Moorman and Matulich 1993). Our motivation to search for nutrition information prediction is based on the notion that when presented with relatively "poor" product nutrition values, more highly motivated consumers should exhibit more negative nutrition attitudes than those with lower motivation (Keller et al. 1997). In our study, we use professionally designed advertisements for a product category not viewed as particularly healthy, but for which the nutrition ad information is considered credible (we discuss this in greater detail subsequently).

\section{Nutrition Motivation Quadratics}

In theory, highly motivated consumers are more involved and form stronger intentions on a given issue than less motivated consumers (Alba and Hutchinson 1987; Brucks, Mitchell, and Staelin 1984). In the context of nutrition, Keller and colleagues (1997) find that motivation has a significant, negative effect on intent when the nutritional value of the product is poor. Furthermore, from our prior rationale and empirical evidence grounded in dual-processing theories (Chaiken 1980; Petty and Cacioppo 1986), we anticipate that such effects will be magnified for extremely motivated consumers, who will strive to avoid foods they perceive as unhealthy. For example, using the heuristicsystematic processing model and protection motivation theory, Griffin and colleagues (2002) find that people become more polarized in their evaluations of health risks when they use systematic processing. They show an upward-sloping quadratic effect between the capacity to gather information (akin to motivation) and attitude and risk beliefs about the outcomes of potentially unhealthy behaviors. In our case, this prior research suggests a negative asymmetric effect of motivation on intent to buy- that is, a downward-sloping curve. Therefore, we expect that motivation to search for information and its quadratic effect will incrementally influence intent to buy the brand beyond their effects on perceived weight gain risk and other control variables.

$\mathrm{H}_{3}$ : There is a negative quadratic relationship between motivation to search for information and intent to buy the brand. At the highest level of motivation to search for information, the effect on consumers' intent is a downward-sloping curve-a negative asymmetric effect-which is in contrast to consumers with low or moderate knowledge levels.

\section{Methodology}

\section{Pretests}

Overview and Ad Claim and Disclosure Development

We conducted pretests with 254 respondents of a statewide consumer panel in the south-central region of the United States to examine ad claim and disclosure manipulations and to develop our measures of knowledge. With primary food shopper as a screening variable, $62 \%$ of the pretest sample were women, the average age of respondents was 51 years, and they had an average of one to three years of college education. From self-reported height and weight, 55\% had a BMI score greater than 25, which places them in the overweight or obese categories (the sample's average BMI score was 27). In addition, most respondents were not familiar with the target snack bar, Krave, advertised in this pretest $(\mathrm{M}=1.67$ on a seven-point familiarity scale). Professionally designed color advertisements were developed on the basis of actual claims made for the snack bar in its advertising.

In this first pretest, respondents were exposed to one of six conditions, representing a 3 (claim: half the fat, onequarter the calories, none) $\times 2$ (disclosure: present, none) between-subjects design. ${ }^{3}$ The half-the-fat claim indicated that the Krave chocolate snack bar had "half the fat of the leading candy bar." The one-quarter-the-calories claim advertised that the Krave chocolate bar had "one-quarter fewer calories than the leading candy bar." (Claim levels were based on actual product ingredients at this point.) Based on prior research (Andrews, Netemeyer, and Burton 1998), the disclosure placed at the bottom of the advertisement indicated that the Krave chocolate bar "[c]ontains 200 calories per serving, an amount determined by the Food and Drug Administration not to be low." Manipulation checks on the claim levels and disclosure (versus controls) were successful $(p<.01)$. In a separate test, perceived weight gain risk (a control variable we used in the main study) was significantly lower $(p<.001)$ for each of the claims (versus the control), suggesting a weight perception benefit, or "halo," due to the claim. However, after reviewing cell means, we decided that the one-quarter-the-calories claim should be changed to a half-the-calories claim to be consistent with the half-the-fat claim in the main study. In addition, on the basis of FDA criteria and given that the actual 200-calorie level of the snack bar was "not low," but could be interpreted as "not high," we increased the stated caloric level of the snack bar to 400 calories to be in the high category for the main study.

\section{Development of Knowledge Measures}

The purpose of the second pretest was to develop measures of objective caloric knowledge and knowledge related to the negative health consequences of obesity for use in the

\footnotetext{
${ }^{3}$ We also tested a Nutrition Facts panel condition with three different levels (new, current, and none). The Nutrition Facts panel was inserted into the Krave advertisement and listed the calorie level in the current version (200 calories), a new version based in part on FDA suggestions (200 calories; $10 \%$ daily value; highlighted in red), or nothing at all. The Nutrition Facts panel treatment did not influence the control variable of perceived weight gain risk or the key dependent variable of intentions in the main study, so we dropped it from subsequent analyses.
} 
main study. We used a multiphased process. In the first phase, we generated a set of items through adaptation of items drawn from Web-based nutrition and obesity quizzes (e.g., Meridian Health, Moses Cone Health System), from selected items from previous published measures (Andrews, Netemeyer, and Burton 1998), and from items we developed specifically for the study. Initially, we tested 36 multiple-choice items with four response categories and a fifth "don't know" response.

A group of three expert judges knowledgeable about fat, nutrition, and the negative consequences of obesity rated items as "very representative," "somewhat representative," or "not representative" to indicate how well they represented our two knowledge domains. We retained the items that two of the three judges rated as at least somewhat representative. Twenty-two items remained after this procedure; next, we administered these to the pretest sample of adult consumers. In the main study, we further trimmed these 22 items to 7, 3 of which assessed negative health effects of fat and obesity (i.e., obesity consequences knowledge) and 4 of which measured caloric knowledge. This focus on calories is consistent with our disclosure manipulation and hypotheses pertaining to these domains. In addition, because of the relationships among calories, fat content, and obesity (Wansink and Chandon 2006b), we included an item on saturated fat for the measures of both the caloric knowledge and the obesity consequences knowledge. As Appendix A shows, these two objective measures produce scores ranging from 0 to 4 for caloric knowledge and from 0 to 3 for obesity consequences knowledge.

To validate our knowledge measures, we also obtained results from a sample that should have been more knowledgeable about nutrition and obesity and compared the findings with our main study sample of adult consumers. The knowledgeable group consisted of graduate and advanced undergraduate students majoring in health and nutrition from a major southern university $(\mathrm{n}=58)$. Their average score on the obesity consequences measure was 2.33, compared with 1.60 for the sample of adult consumers from the main study $(\mathrm{t}=6.53, p<.01)$. For each of the three items in this measure, the health and nutrition majors also scored higher than the adult consumers of the main study (t-values from 3.46 to $4.82, p<.01$ ). The average score on the caloric knowledge measure for this more knowledgeable group was 2.34, compared with 1.49 for the sample of adult consumers from the main study $(\mathrm{t}=5.79$, $p<.01)$. For each of the four items in this measure, the health and nutrition majors scored higher than the adult consumers of the main study (t-values from 3.63 to 7.76, $p<.01)$. These results lend support for the known-group validity of our knowledge measures.

\section{Main Study}

\section{Sample Characteristics and Procedure}

The main study sample consisted of 480 adult consumers recruited and interviewed in malls from three geographically dispersed areas of the country (New York, $n=169$; Chicago, $\mathrm{n}=156$; and Los Angeles, $\mathrm{n}=155$ ). The sample was split evenly by gender, and we used four age quotas to match U.S. Bureau of the Census (2004) projections for those 18 years of age and older. One-quarter of the sample fell into each of the following four age categories: ages 1831 , ages 32-44, ages 45-57, and age 58 and older. Based on actual height and weight measures taken after the interview, $62 \%$ had a BMI score greater than 25, placing them, at minimum, in the overweight category and often in the obese category. (The sample's average BMI score was 27.63.) Most of the sample (59\%) had some college education; $9.2 \%$ were on medically supervised diets, and $21.5 \%$ were on diets that were not medically supervised. Overall, most of the respondents were not familiar with the target chocolate bar, Krave, advertised in the study $(\mathrm{M}=2.83$ on a seven-point familiarity scale), and the majority believed that the chocolate snack bar was either "unhealthy for you" or "neither healthy nor unhealthy for you." Almost all the respondents $(92.1 \%)$ had consumed snack or granola bars in the past six months.

The study procedures followed generally accepted guidelines for advertising copy testing, including the use of a control ad group (cf. Andrews and Maronick 1995). Mall shoppers were first screened for age and then were invited to an interview facility in the mall, where they were randomly assigned to one of six ad conditions, which we describe subsequently. Each respondent then viewed his or her version of the target Krave advertisement, embedded in two clutter advertisements (toothpaste and detergent) in a booklet. When they finished, the booklet was removed from view, and two short-term product and brand recall questions were asked. If respondents answered these correctly, they were shown the target Krave advertisement a second time, followed by cognitive response questions, manipulation checks, and measures of perceived weight gain risk and intent to buy the brand. Respondents then completed demographic questions, the measure of motivation to search for nutrition information, and the measures of knowledge. Before the main study, we conducted a thorough pretest of the procedures with 15 consumers in a mall in a large midwestern metropolitan area. The pretest revealed the need for only minor adjustments to the final instructions used in the main study.

\section{Independent Variables and Controls}

We experimentally manipulated two of the independent variables for the study (i.e., ad claim and disclosure), and we measured three of the independed variables (i.e., obesity consequences knowledge, caloric knowledge, and motivation to search for nutrition information). Thus, respondents were randomly assigned to one of six ad conditions in a 3 (ad claim: no-claim control, half the fat, half the calories) $\times$ 2 (disclosure: none, present) between-subjects design. All advertisements were presented in color, were professionally designed, included the package, had a similar copy length, and began with the words "We packed so much delectable chocolate inside ..." (based on actual Krave advertisements). The no-claim control (i.e., given to the ad control group) went on to discuss chocolate, but it did not present a nutrition claim. The half-the-fat claim stated that Krave had "half the fat of the leading candy bar," and the half-thecalories claim stated that Krave had "half the calories of the leading candy bar." The disclosure condition consisted of either the no-disclosure control or the presence of the fol- 
lowing disclosure at the bottom of the advertisement: "Contains 400 calories per serving, an amount determined by the Food \& Drug Administration to be high." Three of the six ad conditions appear in Appendix B.

A manipulation check on effects of the half-the-fat claim reveals that on a seven-point measure of "fewer (more) fat grams than other snack bars," the half-the-fat claim $(\mathrm{M}=$ 2.54) led to a perception of significantly fewer fat grams than the no-claim control $(\mathrm{M}=3.70$; $\mathrm{t}$-value $=3.18, p<$ $.01)$. Similarly, a manipulation check on the effects of the half-the-calories claim reveals that on a seven-point measure of "fewer (more) calories than other snack bars," the half-the-calories claim $(\mathrm{M}=2.15)$ led to a perception of significantly fewer calories than the no-claim control $(\mathrm{M}=$ $3.93 ; p<.01)$. Finally, a manipulation check on the ad disclosure indicates that on a seven-point scale from "low in calories" to "high in calories," participants exposed to the disclosure $(\mathrm{M}=4.05)$ were significantly more likely to indicate that the Krave bar was high in calories than those not exposed to the disclosure $(\mathrm{M}=3.41$; $\mathrm{t}$-value $=3.47, p<$ $.01)$.

The measured independent variables were the aforementioned obesity consequences and caloric knowledge measures (see Appendix A) and motivation to search for nutrition information. We assessed this latter measure with two seven-point items, which we summed and then averaged $(\mathrm{r}=.72)$. The items read as follows: "I usually am interested in nutritional information in snack bar ads," and "I would like to see additional nutritional information in snack bar ads."

We also gathered several measures for use as control variables because such variables have been suggested to influence the processing and utilization of nutrition information (Moorman 1990). Demographics included gender $(0=$ male, and $1=$ female), education ( six categories from "grade school" to "postgraduate degree"), household income (seven categories from "under $\$ 15,000$ " to "over $\$ 100,000 ")$, and ethnicity ( $0=$ Caucasian, and $1=$ African American, Hispanic, or other). Because BMI has been shown to be related to how consumers process nutrition information on packages and in advertisements (Wansink and Chandon 2006b), we used BMI as a control variable for the prediction of intent to purchase the brand. Respondents also indicated whether they were on a diet $(0=$ no, and $1=$ yes) or a medically supervised diet $(0=$ no, and $1=$ yes $)$, and they indicated their familiarity with the advertised snack bar on a seven-point scale (1 = "not very familiar," and 7 = "very familiar"). We also gathered a seven-point measure of subjective nutrition knowledge because it has been shown to be related to food and nutrition choices in prior research (Wansink and Chandon 2006b); thus, our model tests the effects of objective knowledge that extend beyond any effects of subjective knowledge. The item used was, "Compared to other people, how much do you feel you know about nutrition?" (1 = "almost nothing," and $7=$ "a lot"). Finally, given a focus on weight-related consequences, we used the following seven-point item to measure perceived weight gain risk: "Regularly eating the advertised snack bar may contribute to the risk of gaining weight" ( 1 = "strongly disagree," and 7 = "strongly agree") (Burton et al. 2006). In sum, in addition to the manipulated variables (claim and disclosure) and the linear effects of the knowledge and motivation measures, we used ten control variables in the regression analyses that follow.

\section{Dependent Variable}

The primary dependent variable of interest is the intent to buy the brand. Intent to buy represents a key variable in the study of hierarchy-of-effects frameworks that examine the impact of advertising (Vakratsas and Ambler 1999). We assessed the intent measure with two summed and averaged seven-point responses to the following question: "If available, how likely is it that you would buy the advertised snack bar on one of your shopping trips this month?" ("unlikely/likely"; "not probable/probable"; $r=.91$ ). Table 1 shows summary statistics and correlations among all measured variables.

\section{Cognitive Response Coding}

We used the cognitive responses collected in the main study in the initial analysis to help determine whether respondents indeed engaged in "health halo" processing. After exposure to the Krave advertisements, we asked respondents to provide cognitive responses about the product with the question: "What did the Krave ad say or suggest to you about its product?" We also probed for further information by asking, "What else?" Two independent coders, blind to the specific purpose of the study and experimental conditions, placed the responses into one of five categories: (1) "don't know," (2) "not sure," (3) "nothing" (we treated responses to categories 1-3 as missing values in subsequent analyses), (4) responses that represented direct "playback" from the ad copy (i.e., "It has half the fat," "It has half the calories"), and (5) responses considered positive inferences or "health halos." The coders viewed five categories of the verbatim responses as health halos: (1) healthy product, healthful (e.g., "It's healthy and not many calories," "That it is healthy for you"); (2) product is good for you, good for your body, and so on (e.g., "That it was wholesome and good for your body," "It's good for you"); (3) losing weight (e.g., "That it would help you lose weight," "Lose weight"); (4) no calories, few calories, low calories (e.g., "It had low calories and tastes good," "That it has no calories and the line ... 'Krave something better"'); and (5) no fat, low fat (e.g., "That it is low in fat," "No fat"). The proportional reduction in loss (PRL) coder reliability was .99, indicating a high level of interrater consistency (Rust and Cooil 1994).

\section{Data Modeling Checks}

Although we conducted our study as a field experiment, the analytical approach we take in presenting our results is hierarchical regression analysis. We use this approach to test the hypothesized quadratic effects of obesity consequences knowledge, caloric knowledge, and motivation to search for nutrition information, after accounting for the effects of the manipulated variables (claim and disclosure), the control variables, and the linear effects of obesity consequences knowledge, caloric knowledge, and motivation to search for nutrition information on intent to buy the brand. In addition, with the dichotomous experimental manipulations (i.e., disclosure present or absent and claim present or absent), regression will yield the same/similar results as an analysis of variance/multivariate analysis of variance (ANOVA/ MANOVA) approach for the dichotomous manipulations 


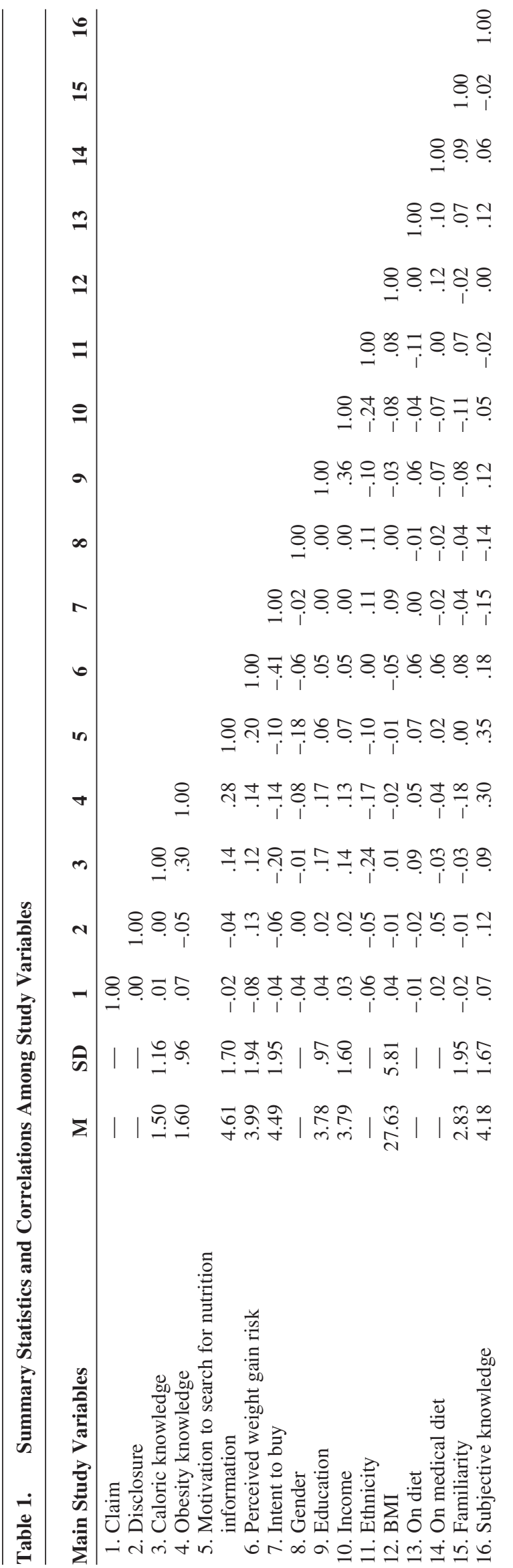

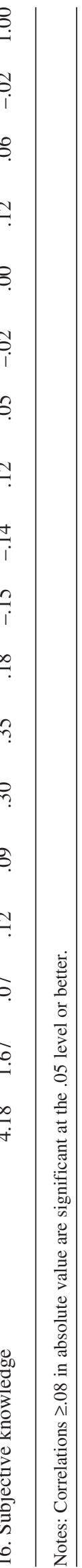


(Pedhazur 1997). Still, we conducted two data preparation checks before estimating our models.

First, we checked to determine whether the claim manipulation at three levels (no-claim control, half the fat, and half the calories) could be collapsed into a two-level variable for the regression analyses. An ANOVA revealed that there were mean-level differences for the dependent variable of intent to buy the brand between the no-claim control condition and the half-the-fat and half-the-calories conditions. However, there were no mean-level differences for this dependent variable between the half-the-fat and half-the-calories conditions $(p>.10)$, nor did the variances of the dependent variable differ between the half-the-fat and half-the-calories conditions $(p>.10)$. As such, we combined the half-the-fat and half-the-calories conditions into one level and created a 0 (no claim) and 1 (claim present as half the fat or half the calories) dummy variable for the ad claim variable's effect on intent to buy the brand.

Second, we mean-centered all independent variables (manipulated, control, and linear effects of the knowledge and motivation variables) before regression model estimation, and we squared the mean-centered knowledge and motivation variables, respectively, to create their quadratic effects (Cohen et al. 2003).

\section{Analysis and Results}

\section{Cognitive Process and Belief Checks for Consumer Misperceptions}

To address whether there were claim-related generalizations that suggested "health halo" processing, we first examined the cognitive responses to the question, "What did the Krave ad say or suggest to you about its product?" The strongest test of the "health halo" inference pertains to differences between a claim-only condition (with either half-the-fat or half-the-calories claim) without a disclosure versus the control condition, in which there is not a claim about fat or calories or a disclosure. Thus, our initial test involved only the claim conditions in which there was no other manipulated information in the advertisement (e.g., a disclosure) to weaken the effect of the claim. When we used either a half-the-fat claim or a half-the-calories claim, $22 \%$ of the participants made a positive "health halo" inference ("It's healthy," "It's good for you"), whereas in the control condition, $0 \%$ made "health halo" inferences. This difference in percentages was significant $\left(\chi^{2}=6.91, p<\right.$ .01 ), suggesting that health halo inferencing did occur. ${ }^{4}$ In

"To check further whether "health halo" processing was likely, we conducted a brief qualitative study in which four interviewers exposed 12 adult consumer respondents (5 men and 7 women; ages 27-69 years) to both of the claim-only conditions of the Krave advertisements (i.e., half the fat and half the calories). Consistent with McQuarrie and Mick (1999), we embedded the advertisements in two clutter advertisements (i.e., detergent and toothpaste) and counterbalanced them such that each respondent saw a different ordering of all advertisements. We asked respondents two open-ended questions (and a probe) for each Krave advertisement; we audiotaped their responses and then content-analyzed them. The two questions read as follows: (1) "What does the ad say or suggest to you?" and (2) "What does the ad say or suggest about the product?" We phrased the probe as follows: "Is there anything else the ad might suggest about using the product?" We classified responses as halo processing if respondents made statements that indicated a positive health interpretation beyond just ad copy playback (e.g., half the fat, half the calories). Examples of typical nonplayback responses were "good for you and more healthy for you"; "it addition, on a seven-point scale ranging from "healthy for you" to "unhealthy for you," respondents exposed to either claim $(\mathrm{M}=2.98)$ were significantly more likely to report that the Krave snack bar was "healthy for you" than those not exposed to the claims $(\mathrm{M}=3.74$; $\mathrm{t}$-value $=1.98, p<$ .05 ), offering quantitative support for "health halo" processing.

Finally, as we expected, exposure to the ad claims produced a significant, negative effect on the perceived weight gain risk belief $(\beta=-.37, p<.05)$, whereas the ad disclosure resulted in a significant, positive effect on perceived weight gain risk $(\beta=.50, p<.01)$. These results show the effects of the ad-based claim and disclosure manipulations on consumer perceptions of weight gain risk. In turn, as we show in Table 2, higher perceived weight gain risk resulted in a significantly reduced intention to buy the advertised snack bar $(\beta=-.38, p<.01)$.

\section{Model Estimation and Tests of Hypotheses}

To test the predictions in $\mathrm{H}_{1}, \mathrm{H}_{2}$, and $\mathrm{H}_{3}$, we used hierarchical regression analyses (Cohen et al. 2003). To accomplish this, we estimated two models. The first model estimated the main effects of all independent and control variables on the dependent variable, as well as the linear (main) effects of the knowledge and motivation measures. This model (Model 1 in Table 2) shows that the control variable of perceived weight gain risk $(\beta=-.38, t=8.73$, $p<.01)$ and the linear effect of caloric knowledge $(\beta=-.26$, $\mathrm{t}=3.14, p<.01)$ largely account for the bulk of this model's explained variance.

The results pertaining to Model 2 are of greater interest because they assess the incremental variance explained in intent to buy the brand by adding quadratic effects hierarchically to Model 1 (Cohen et al. 2003). ${ }^{5}$ As Table 2 shows, all three hypothesized quadratics were significant. The caloric knowledge quadratic term $\left(\mathrm{H}_{1}: \beta=-.11, \mathrm{t}=1.69\right.$, $p<.05)$, the obesity consequences knowledge quadratic term $\left(\mathrm{H}_{2}: \beta=-.17, \mathrm{t}=2.01, p<.05\right)$, and the motivation to search for nutrition information quadratic term $\left(\mathrm{H}_{3}\right.$ : $\beta=$ $-.04, \mathrm{t}=1.51, p<.10$ ) (all one-tailed tests) were significant and in the predicted direction. That is, all paths showed the predicted downward-sloping curves (asymmetric or quadratic effect) at the highest levels for these predictor variables. This model including quadratic effects explained $24 \%$ of the variance in intent to buy the brand and a significant amount beyond the variance explained by the main effects of all variables observed for Model 1. (Note also that in Models 1 and 2, the linear effects of both motivation and obesity knowledge are nonsignificant.) As Figure 1 displays, regression plots of the quadratic effects for obesity consequences knowledge (which has a minimum level of 0 and maximum of 3 ) and for caloric knowledge (which has

\footnotetext{
is a low calorie snack bar that is supposed to have good taste"; and "a good, tasty, healthy treat." Based on this classification, 4 of $12(33.3 \%)$ respondents made a "health halo" inference for the half-the-calories advertisement, and 6 of $12(50 \%)$ made a "health halo" inference for half-the-fat advertisement. Thus, we found evidence of halo processing from a sample of respondents independent from that of our main study.

${ }^{5}$ The objective caloric knowledge scale ranges from zero (no correct responses) to four (all correct responses), and the obesity consequences scale ranges from zero to three correct responses. Motivation is a multiitem measure composed of two seven-point scale items.
} 
Table 2. Hierarchical Regression Results

\begin{tabular}{|c|c|c|c|c|}
\hline & \multicolumn{2}{|c|}{ Model 1} & \multicolumn{2}{|c|}{ Model 2} \\
\hline & Coefficient & t-Value & Coefficient & t-Value \\
\hline Claim $\rightarrow$ intent to buy brand & $-.27(-.07)$ & $1.59 *$ & $-.27(-.07)$ & $1.61 *$ \\
\hline Disclosure $\rightarrow$ intent to buy brand & $-.04(-.01)$ & .25 & $-.07(-.02)$ & .45 \\
\hline Gender $\rightarrow$ intent to buy brand & $-.24(-.06)$ & $1.46^{*}$ & $-.27(-.07)$ & $1.67 * *$ \\
\hline Education $\rightarrow$ intent to buy brand & $-.04(-.02)$ & .50 & $-.03(-.01)$ & .40 \\
\hline Income $\rightarrow$ intent to buy brand & $-.01(-.01)$ & .15 & $-.01(-.01)$ & .06 \\
\hline Ethnicity $\rightarrow$ intent to buy brand & $-.18(-.04)$ & .94 & $-.11(-.03)$ & .58 \\
\hline BMI $\rightarrow$ intent to buy brand & $.02(.07)$ & $1.66 * *$ & $.02(.06)$ & $1.50 *$ \\
\hline Diet $\rightarrow$ intent to buy brand & $-.24(-.05)$ & 1.23 & $-.21(-.04)$ & 1.06 \\
\hline Medical diet $\rightarrow$ intent to buy brand & $.31 \quad(.05)$ & 1.11 & $.25(.04)$ & .90 \\
\hline Familiarity $\rightarrow$ intent to buy brand & $-.05(-.05)$ & 1.21 & $-.05(-.05)$ & 1.30 \\
\hline Subjective nutrition knowledge $\rightarrow$ intent to buy brand & $-.08(-.07)$ & $1.45^{*}$ & $-.06(-.05)$ & 1.09 \\
\hline Perceived weight gain risk $\rightarrow$ intent to buy brand & $-.38(-.38)$ & $8.73 * * *$ & $-.37(-.37)$ & $8.56 * * *$ \\
\hline Caloric know $\rightarrow$ intent to buy brand & $-.26(-.14)$ & $3.14 * * *$ & $-.22(-.12)$ & $2.60 * * *$ \\
\hline Obesity know $\rightarrow$ intent to buy brand & $-.07(-.03)$ & .70 & $-.11(-.06)$ & 1.15 \\
\hline Motivation $\rightarrow$ intent to buy brand & $-.02(-.02)$ & .36 & $-.01(-.01)$ & .10 \\
\hline $\mathrm{H}_{1}$ : Caloric know ${ }^{2} \rightarrow$ intent to buy brand & - & - & $-.11(-.07)$ & $1.69 * *$ \\
\hline $\mathrm{H}_{2}$ : Obesity know ${ }^{2} \rightarrow$ intent to buy brand & - & - & $-.17(-.09)$ & $2.01 * *$ \\
\hline $\mathrm{H}_{3}:$ Motivation ${ }^{2} \rightarrow$ intent to buy brand & - & - & $-.04(-.07)$ & $1.51 *$ \\
\hline $\mathrm{R}^{2}:$ Intent to buy brand & \multicolumn{2}{|c|}{.22} & \multicolumn{2}{|c|}{.24} \\
\hline $\begin{array}{l}* p<.10 \text { (one-tailed) } \\
* * p<.05 \text { (one-tailed) } \\
* * * p<.01 \text { (one-tailed). } \\
\text { Notes: Standardized path estimates are in parentheses. }\end{array}$ & & & & \\
\hline
\end{tabular}

minimum and maximum values of 0 and 4 , respectively) show that nonlinear negative asymmetric effects occur. A similar plot of the quadratic effect for motivation to search for information shows that when motivation is greater than 6 , the nonlinear negative asymmetric effect materializes.

\section{Discussion}

Given the severe health consequences of being overweight and/or obese (CDC 2008), this study contributes to the literature on consumer processing of nutrition information by examining important effects for increasingly higher levels of nutrition knowledge type and motivation. In doing so, we go beyond the traditional focus on just high- and lowknowledge and -motivation groups from median splits. The results show that beyond the effects of the ad claims and disclosures, control variables, and the linear (main) effects of the knowledge and motivation measures, there were significant curvilinear (quadratic) effects for caloric knowledge, obesity consequences knowledge, and motivation to search for nutrition information on intent to buy the advertised high-calorie snack bar. This implies a strengthening of the negative relationship for intent for consumers who are at the highest levels of caloric knowledge, obesity consequences knowledge, and motivation (i.e., the "nutrition elite"). In addition, both qualitative (cognitive response process checks) and quantitative (hierarchical regression) findings combine to indicate that exposure to the relative nutrition ad claims can lead to potential "health halos." We now more fully discuss the roles and implications of these internal and external sources in influencing intentions to buy.

\section{Internal Characteristics}

In terms of characteristics internal to the consumer, the results indicate significant roles for the highest levels of two types of knowledge (i.e., caloric and obesity consequences) and self-reported motivation to search for nutrition information separate from the impact of claims and disclosures, control variables, and the linear (main) effects of knowledge and motivation. As a result of such effects, attempting to reach higher levels of these constructs may be crucial for public health officials, given concerns about low knowledge and insufficient motivation to regulate behavioral eating patterns (e.g., FDA 2006). As related to calorie consumption and weight gain patterns, this concern is being reinforced by increasing empirical evidence that the majority of consumers underestimate calorie and fat levels for less healthy meals and items consumed away from home (Chandon and Wansink 2007a). Our findings also support contentions that different types of knowledge may be needed to produce the greatest potential effect in fighting obesity (Wansink 2005, p. 18) and, if at all possible, that efforts should be made to design educational programs to increase consumer knowledge of nutrition and the consequences of obesity (e.g., Baronowski et al. 2003).

In addition, most prior research examining knowledge and nutrition motivation constructs in experiments has used ANOVA techniques (cf. Andrews, Netemeyer, and Burton 1998). Although beneficial in studying experimental treatment levels, the use of such an approach may restrict opportunities to examine quadratic and "higher-order" effects. Such ANOVA approaches, with the traditional high-low groups, may show one factor (e.g., nutrition knowledge) as 
Figure 1. Quadratic Effects of Obesity Consequences Knowledge, Caloric Knowledge, and Motivation to Search on Intent to Buy
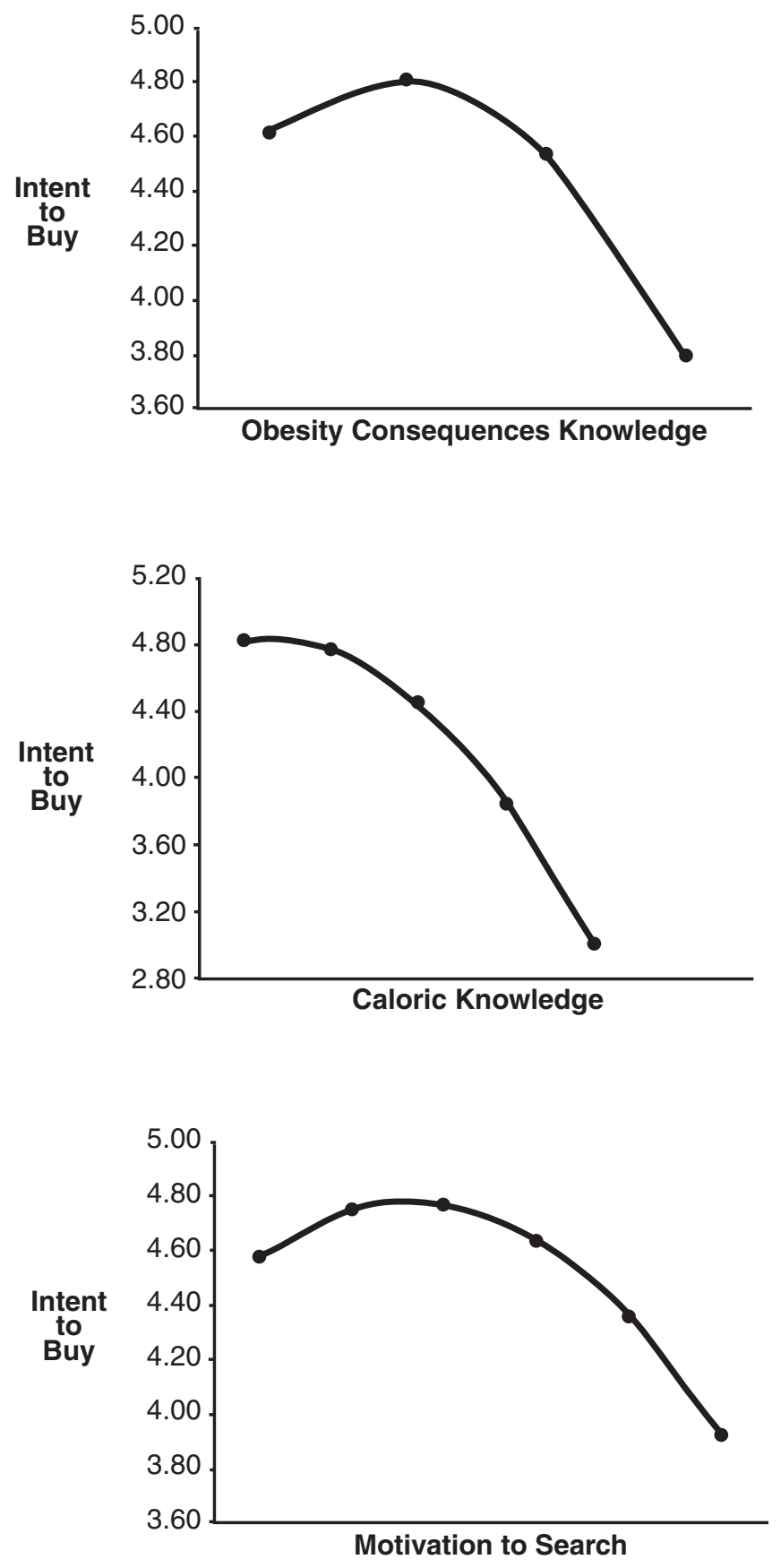

Notes: The intent-to-buy dependent variable shown in the three plots is assessed on a seven-point scale ranging from 1 to 7 . The objective caloric and obesity consequences knowledge scales range from 0 to 4 correct responses and 0 to 3 correct responses, respectively. (Items used for these measures appear in Appendix A.) The Obesity Consequences Knowledge plot is based on the predicted values from the following regression equation: Intent to Buy $=4.62+.431$ (Obesity Consequences Knowledge) -.234 (Obesity Consequences Knowledge ${ }^{2}$ ), where 4.62 is the intercept (constant), Obesity Consequences Knowledge is the linear effect of obesity consequences knowledge, and Obesity Consequences Knowledge 2 is the quadratic effect of obesity consequences knowledge, as the downward-sloping "negative asymmetric effect" suggests. The Caloric Knowledge plot is based on predicted values from the following regression equation: Intent to Buy $=4.83+.078$ (Obesity Consequences Knowledge) -.134 (Obesity Consequences Knowledge $^{2}$ ), where 4.83 is the intercept (constant), Caloric Knowledge is the linear effect of caloric knowledge, and Caloric Knowledge ${ }^{2}$ is the quadratic effect of caloric knowledge, as the downward-sloping "negative asymmetric effect" suggests. The Motivation to Search plot is based on the predicted values from the following regression equation: Intent to Buy $=3.79-.546$ (Motivation) +.75 (Motivation'), where 3.79 is the intercept (constant), Motivation is the linear effect of motivation, and Motivation ${ }^{2}$ is the quadratic effect of motivation, as the downward-sloping "negative asymmetric effect" suggests. 
dependent on another (e.g., nutrition motivation) when responses from higher levels of a given factor may be sufficient for the intended effects. The results from our regression analyses indicate an improved fit for our model containing significant quadratic effects for caloric knowledge, obesity consequences knowledge, and motivation on intent to buy the advertised, high-calorie snack bar. As Figure 1 depicts, a substantial deviation from linearity is illustrated through the strengthening of the negative relationship for intent for consumers at the highest levels of both motivation and objective knowledge. Such an escalating impact of knowledge and motivation at the highest levels has not been reported in prior studies and may indicate that, unfortunately, consumer nutrition education may be most successful in reaching its objectives only when driving consumer levels into the upper tiers of knowledge and motivation.

\section{The Role of External Information}

Package nutrition and health claims can result in consumers' misperceptions and thus reduce their perceived likelihood of disease risk (Kozup, Creyer, and Burton 2003). Such misperceptions can result in an underestimation of calories, leading to greater intake of less healthy foods and unrealized increases in calorie consumption (Chandon and Wansink 2007a). In our ad-based research, reader-response interviews suggest that relative nutrition claims can create a positive "halo effect." They can also lead to a reduced likelihood of perceived weight gain risk, which in turn increases the intention to buy food that is not viewed as particularly healthy. It is such misattributions about calorie levels potentially that lead consumers to underestimate their consumption because of unrealized calories (Wansink and Chandon 2006b). Furthermore, initial analyses indicated that claims about reduced calories and reduced fat operated in an indistinguishable way for these consumers, a finding of interest to public health officials concerned with having consumers focus greater attention on calories relative to the past emphasis on fat levels (FDA 2004, 2006).

However, presenting external information in the form of a prominent ad disclosure counterbalances the potential misperceptions about the perceived risk of weight gain associated with the product. In our case, the disclosures are effective independent of the claims and regardless of the internal caloric or obesity consequences knowledge or motivation levels. In general, our findings support the role of concisely written and prominently displayed disclosure statements for less healthy products in overcoming misleading perceptions for all consumers, not just those who are more motivated and knowledgeable. 6

\section{Implications for Nutrition Media Campaigns and Public Policy}

To help counter the pattern of increased obesity, it seems clear that a multifaceted, integrated, and comprehensive approach is needed, involving market-based solutions (e.g.,

\footnotetext{
${ }^{6}$ Other research involving products viewed as relative healthy (e.g., soup) found that ad disclosure of high sodium levels was dependent on ad claims and nutrition knowledge levels (Andrews, Burton, and Netemeyer 2000).
}

reduced serving sizes, 100-calorie packs, standardized front-of-package icons), possible nutrition education, disclosures, financial incentives, and community-based programs (see Economos et al. 2007; Seiders and Petty 2004). In our study, and consistent with the need for a more integrated approach, the effects of both internal (knowledge and motivation) and external (disclosures) constructs are evident and relatively independent of each another, suggesting the need to address both types of variables in the fight against obesity. Comprehensive nutrition education media campaigns (e.g., the CDC's VERB program, the Department of Health and Human Services' Small Steps and Childhood Obesity Prevention programs, the Weight Watchers Point System) can be important elements in increasing nutrition knowledge and motivation. Yet strategic message platforms, message heuristics, media planning, budget issues, and measurement and evaluation decisions are all additional factors essential in the success of such campaigns (cf. Foley and Pechmann 2004). Moreover, careful segmentation is critical in enhancing nutrition education, knowledge, and motivation, because such elements (as with obesity risks) can vary with education, gender, BMI, income, ethnicity, and age (Seiders and Petty 2004).

In addition, an understanding of existing levels of nutrition knowledge and motivation is important because these elements are likely to affect the "reasonable consumer's" interpretation of potentially misleading nutrition claims-a point to be considered in the FTC's (1994) "Enforcement Policy Statement on Food Advertising." Yet, as found in our research, the accuracy of responses to many of our questions pertaining to caloric content of foods and weight was alarmingly low (e.g., less than $50 \%$ knew the number of daily calories recommended for most people, though this information is available on every Nutrition Facts panel on all food products). Furthermore, as the correlations in Table 1 show, both caloric and obesity consequences knowledge levels were significantly higher for those with higher incomes (.17 and .17 , respectively) and higher education (.14 and .13, respectively) and were significantly lower for non-Caucasians (-.24 and -.17 , respectively). However, it is clear from our results that higher levels of knowledge and motivation, even for those who are already relatively knowledgeable, offer ever escalating (nonlinear) benefits to nutrition perceptions and healthy consumer decision making. Yet, clearly, the concern is with other segments achieving such higher levels of knowledge and motivation, and market-based solutions (e.g., 100-calorie packs, front-ofpackage nutrition "traffic lights") may present a more viable option for such consumers.

\section{Limitations}

Although we followed recommended procedures for ad copy tests, used a sample from several major markets reflecting U.S. demographics, and employed professionally designed ad stimuli, the generalizability of the findings may be limited in ways specific to copy test research. For example, we used specific copy claims related to calories and fat and a disclosure consistent with recent concerns about calorie awareness (FDA 2006); thus, it is possible that findings could vary for different claims and different disclosure types and levels. The results might also be different for other study populations (e.g., rural U.S. consumers, inter- 
national markets). In addition, the study conditions and results may not extend to campaign-length exposure levels, which might affect the strength of effects, or to other variables beyond perceived weight gain risk and intent, such as purchase and product consumption rates. Marketbased tracking studies that address these issues related to generalizability may be of interest. Although consistent with theory and many marketing applications (e.g., Agustin and Singh 2005; Zuckerman and Chaiken 1998), the quadratic effects we found for motivation and objective knowledge in this ad-based study could be further examined in research involving other measures of motivation and knowledge and for nutrition labeling and other product choice contexts.

\section{Further Research}

Additional research opportunities exist regarding internal and external consumer characteristics related to product perceptions and health halos. There may be many diverse drivers of caloric, weight-related, or health halo effects (e.g., awareness of serving sizes, consumption contexts, external information in media and advertisements) that can lead to misperceptions of calorie levels. Further research aimed at understanding the relative strength of such characteristics and the external and internal forces that most effectively ameliorate these effects is of interest. For example, the linear and quadratic effects of motivation and knowledge domains, coupled with the low mean levels on our objective knowledge measures, raise further issues regarding specific efforts to increase these levels. Research might address the relative effectiveness of different approaches (and even the very worth) of disseminating information across population segments, given that some will have lower knowledge and motivation and are at greater risk of dire consequences related to obesity. At the same time, given that effects in this study extend to people at even the highest levels of knowledge and motivation, benefits might be derived from more complex information targeted at better-informed segments. Such efforts can help increase the understanding of one of the most serious public health issues in the United States today, namely, reducing obesity.

\section{Appendix A: Objective Knowledge Domain Questions7}

\section{Caloric Knowledge}

-For a 100-gram serving of the following foods, which one food would contain the least calories?

1. Plain (regular) salted potato chips.

2. Nacho flavor tortilla chips.

3. Plain salted pretzels.

\footnotetext{
${ }^{7}$ The correct response for each question appears in bold. The set of items is drawn from Web-based quizzes (e.g., Meridian Health, Moses Cone Health System), selected items from previous published measures related to nutrition knowledge (Andrews, Netemeyer, and Burton 1998; Burton, Biswas, and Netemeyer 1994; Levy, Fein, and Stephenson 1993), and items developed by the authors.
}

4. Soft, uncoated, peanut butter granola bar.

5. Don't know.

Response: $\mathbf{2 9 . 4 \%}$ correct.

-For the majority of American consumers, how many calories a day are recommended in a daily diet to maintain a healthy weight?
1. About 500 .
2. About 1000 .
3. About 2000.
4. About 3000.
5. About 3500 .
6. Don't know.

Response: $\mathbf{4 5 . 8 \%}$ correct.

-Saturated fats are usually found in:

1. Vegetables and vegetable oils.

2. Animal products like meat and dairy.

3. Grain products such as bread and cereal.

4. None of the above.

5. Don't know.

Response: $\mathbf{4 9 . 4 \%}$ correct.

-Which kind of fat is higher in calories?

1. Saturated fats.

2. Polyunsaturated fats.

3. They are both the same.

4. None of the above.

5. Don't know.

Response: $\mathbf{2 4 . 4 \%}$ correct.

\section{Obesity Consequences Knowledge}

-Which of these serious health problems has/have been linked to obesity?

1. Type 2 diabetes.

2. Heart disease.

3. High blood pressure.

4. Stroke.

5. All of the above.

6. Don't know.

Response: $\mathbf{6 8 . 5 \%}$ correct.

-In which area of the body does a high percentage of fat pose the greatest health risks?

1. Thighs and arms.

2. The abdominal region.

3. The buttocks.

4. The chin and neck area.

5. Don't know.

Response: $\mathbf{5 9 . 2 \%}$ correct.

-Which kind of fat is more likely to raise people's blood cholesterol level?

1. Saturated fats.

2. Polyunsaturated fats.

3. Both saturated and polyunsaturated fats.

4. None of the above.

5. Don't know.

Response: $\mathbf{3 2 . 3 \%}$ correct. 
Appendix B. Selected Ad Claim and Disclosure Treatments

A: No Claim, No Disclosure Treatment

We packed so much

DELECTABLE CHOCOLATE TASTE INSIDE,

we know you

WON'T BE ABLE TO RESIST.

Once you bite into the sweet,

rich chocolate seduction of a

Kellogg's Krave bar, you'll

understand.

KRAVE SOMETHING BETTER ${ }^{\text {n }}$

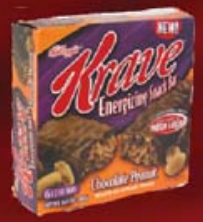

B: Half-the-Fat Claim, No Disclosure Treatment

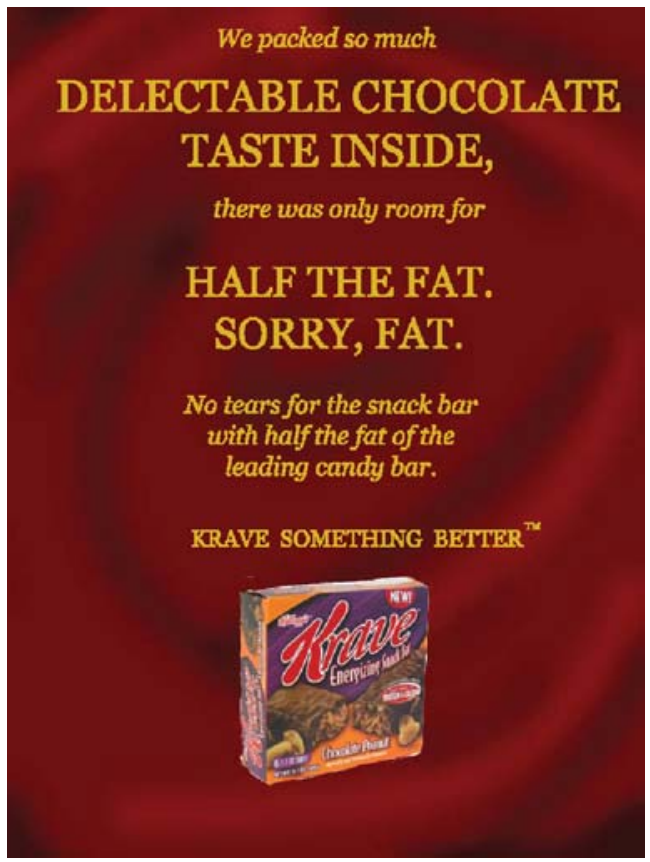

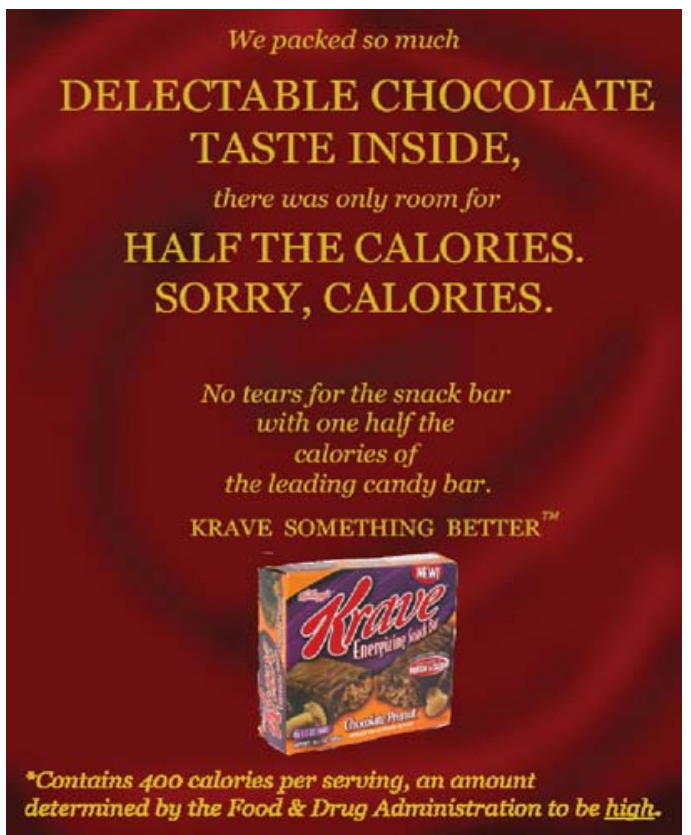

Notes: These represent three of the six possible ad treatment conditions in the 3 (claim: no claim, half the fat, half the calories) $\times 2$ (disclosure: none, present) design. 


\section{References}

Agustin, Clara and Jagdip Singh (2005), "Curvilinear Effects of Customer Loyalty Determinants in Relational Exchanges," Journal of Marketing Research, 42 (February), 96-108.

Alba, Joseph W. and J. Wesley Hutchinson (1987), "Dimensions of Consumer Expertise," Journal of Consumer Research, 13 (March), 411-54.

Anderson, E.W. (1998), "Customer Satisfaction and Word-ofMouth," Journal of Service Research, 1 (1), 5-17.

Andrews, J. Craig, Scot Burton, and Richard G. Netemeyer (2000), "Are Some Comparative Nutrition Claims Misleading? The Role of Nutrition Knowledge, Ad Claim Type, and Disclosure Conditions," Journal of Advertising, 29 (Fall), 29-42.

, Srinivas Durvasula, and Syed Akhter (1990), “A Framework for Conceptualizing and Measuring the Involvement Construct in Advertising Research," Journal of Advertising, 19 (4), $27-40$.

and Thomas J. Maronick (1995), "Advertising Research Issues from FTC Versus Stouffer Foods Corporation," Journal of Public Policy \& Marketing, 14 (Fall), 301-309.

— Richard G. Netemeyer, and Scot Burton (1998), "Consumer Generalization of Nutrient Content Claims in Advertising," Journal of Marketing, 62 (October), 62-75.

Baronowski, Tom, Karen W. Cullen, Theresa Nicklas, Deborah Thompson, and Janice Baronowski (2003), "Are Current Health Behavioral Change Models Helpful in Guiding Prevention of Weight Gain Efforts?" Obesity Research, 11 (October), $23 \mathrm{~s}-43 \mathrm{~s}$.

Batra, Rajeev and Michael L. Ray (1986), "Situational Effects of Advertising Repetition: The Moderating Influence of Motivation, Ability, and Opportunity to Respond," Journal of Consumer Research, 12 (March), 432-45.

Brucks, Merrie, Andrew A. Mitchell, and Richard Staelin (1984), "The Effect of Nutritional Information Disclosure in Advertising: An Information Processing Approach," Journal of Public Policy \& Marketing, 3, 1-25.

Burton, Scot, Abe Biswas, and Richard G. Netemeyer (1994), "Effects of Alternative Nutrition Label Formats and Nutrition Reference Information on Consumer Perceptions, Comprehension, and Product Evaluations," Journal of Public Policy \& Marketing, 13 (Spring), 36-47.

_- Elizabeth Creyer, Jeremy Kees, and Kyle Huggins (2006), "Attacking the Obesity Epidemic: The Potential Health Benefits of Providing Nutrition Information in Restaurants," American Journal of Public Health, 96 (September), 1669-75.

CDC (2008), "Overweight and Obesity," U.S. Department of Health and Human Services, (July), (accessed January 16, 2009), [available at http://www.cdc.gov/nccdphp/dnpa/obesity/ index.htm].

Chaiken, Shelly (1980), "Heuristic Versus Systematic Information Processing and the Use of Source Versus Message Cues in Persuasion," Journal of Personality and Social Psychology, 39 (5), 752-66.

Chandon, Pierre and Brian Wansink (2007a), "The Biasing Health Halos of Fast-Food Restaurant Health Claims: Lower Calorie Estimates and Higher Side-Dish Consumption Intentions," Journal of Consumer Research, 34 (October), 301-314.

and (2007b), "Is Obesity Caused by Caloric Underestimation? A Psychophysical Model of Meal Size Estimation," Journal of Marketing Research, 44 (February), 84-99.
Cohen, Jacob, Patricia Cohen, Stephen G. West, and Leona S. Aiken (2003), Applied Multiple Regression/Correlation Analysis for the Behavioral Sciences, 3d ed. Mahwah, NJ: Lawrence Erlbaum Associates.

Economos, Christina D., Raymond R. Hyatt, Jeanne P. Goldberg, Aviva Must, Elena N. Naumova, Jessica J. Collins, et al. (2007), "A Community Intervention Reduces BMI z-Score in Children: Shape Up Sommerville First Year Results," Obesity, 15 (5), 1325-36.

FDA (2004), "HHS Unveils FDA Strategy to Help Reduce Obesity: New 'Calories Count' Approach Builds on HHS' Education Research Efforts," press release, (March 12), (accessed January 16, 2009), [available at http://www.fda.gov/bbs/topics/ news/2004/hhs_031204.html].

(2006), "The Keystone Forum on Away-from-Home Foods: Opportunities for Preventing Weight Gain and Obesity," (accessed January 16, 2009), [available at http://www. docuticker.com/2006/06/keystone-forum-on-away-from-homefoods.html].

Flegal, Katherine M., Barry I. Graubard, David F. Williamson, and Mitchell H. Gail (2005), "Excess Deaths Associated with Underweight, Overweight, and Obesity," Journal of the American Medical Association, 293 (15), 1861-67.

Foley, Diane and Cornelia Pechmann (2004), "The National Youth Anti-Drug Media Campaign Copy Test System," Social Marketing Quarterly, 10 (Summer), 34-42.

FTC (1994), "Enforcement Policy Statement on Food Advertising," (May), (accessed January 16, 2009), [available at http://www.ftc.gov/bcp/policystmt/ad-food.shtm].

(2002), "Weight Loss Advertising: An Analysis of Current Trends," report, (September), (accessed January 16, 2009), [available at http://www.ftc.gov/bcp/reports/weightloss.pdf]

(2007), "Weighing In: A Check-Up on Marketing, SelfRegulation, and Childhood Obesity," public forum workshop (July 18).

Ganzach, Yoav (1997), "Misleading Interaction and Curvilinear Terms," Psychological Methods, 2 (3), 235-47.

Griffin, Robert J., Kurt Neuwirth, James Giese, and Sharon Dunwoody (2002), "Linking the Heuristic-Systematic Model and Depth of Processing," Communication Research, 29 (6), 705-732.

Howlett, Elizabeth H., Scot Burton, and John Kozup (2008), "How Modification of the Nutrition Facts Panel Influences Consumers at Risk for Heart Diseases: The Case of Trans Fat," Journal of Public Policy \& Marketing, 27 (Spring), 83-97.

Hoy, Mariea Grubbs and J. Craig Andrews (2004), “Adherence of Prime-Time Televised Advertising Disclosures to the "Clear and Conspicuous' Standard: 1990 Versus 2002," Journal of Public Policy \& Marketing, 23 (Fall), 170-82.

Jacobson, Michael F. (2006), "The Two Faces of the Food Industry," Nutrition Action Healthletter, (October), 2.

Keller, Scott B., Mike Landry, Jeanne Olson, Anne M. Velliquette, Scot Burton, and J. Craig Andrews (1997), "The Effects of Nutrition Package Claims, Nutrition Facts Panels, and Motivation to Process Nutrition Information on Consumer Product Evaluations," Journal of Public Policy \& Marketing, 16 (Fall), 256-69.

Kozup, John, Elizabeth H. Creyer, and Scot Burton (2003), "Making Healthful Food Choices: The Influence of Health Claims and Nutrition Information on Consumers' Evaluations of Packaged Food Products and Restaurant Menu Items," Journal of Marketing, 67 (April), 19-34. 
Levy, Alan S., Sara B. Fein, and Marilyn Stephenson (1993), "Nutrition Knowledge Levels About Dietary Fats and Cholesterol: 1983-1988," Journal of Nutrition Education, 25 (3), 60-66.

MacCallum, Robert C. and Corrine M. Mar (1995), "Distinguishing Between Moderator and Quadratic Effects in Multiple Regression," Psychological Bulletin, 118 (3), 405-421.

McQuarrie, Edward F. and David G. Mick (1999), "Visual Rhetoric in Advertising: Text, Interpretive, Experimental, and Reader-Response Analyses," Journal of Consumer Research, 26 (1), 37-54.

Mitra, Anu, Manoj Hastak, Gary T. Ford, and Debra Jones Ringold (1999), "Can the Educationally Disadvantaged Interpret the FDA-Mandated Nutrition Facts Panel in the Presence of an Implied Health Claim?" Journal of Public Policy \& Marketing, 18 (Spring), 106-117.

Moore, Elizabeth S. (2007), "Perspectives on Food Marketing and Obesity: Introduction to the Special Section," Journal of Public Policy \& Marketing, 26 (Fall), 157-61.

Moorman, Christine (1990), "The Effects of Stimulus and Consumer Characteristics on Utilization of Nutrition Information," Journal of Consumer Research, 17 (December), 362-74.

(1996), “A Quasi Experiment to Assess the Consumer and Informational Determinants of Nutrition Information Processing Activities: The Case of the Nutrition Labeling Education Act," Journal of Public Policy \& Marketing, 15 (Spring), $28-44$.

, Kristen Diehl, David Brinberg, and Blair Kidwell (2004), "Subjective Knowledge, Search Locations, and Consumer Choice," Journal of Consumer Research, 31 (December), 673-80.

_ and Erika Matulich (1993), “A Model of Consumers' Preventive Health Behaviors: The Role of Health Motivation and Health Ability," Journal of Consumer Research, 20 (September), 208-228.

National Institutes of Health (2006), "Weight-Loss and Nutrition Myths: How Much Do You Really Know?" (accessed January 16, 2009), [available at http://win.niddk.nih.gov/publications/ myths.htm].

Pedhazur, Elazur J. (1997), Multiple Regression in Behavioral Research: Explanation and Prediction, 3d ed. Fort Worth, TX: Harcourt Brace.
Petty, Richard E. and John T. Cacioppo (1986), Communication and Persuasion: Central and Peripheral Routes to Attitude Change. New York: Springer-Verlag.

Reynolds, Thomas J. and Jerry C. Olson (2001), Understanding Decision Making: The Means-End Approach to Marketing and Advertising Strategy. Mahwah, NJ: Lawrence Erlbaum Associates.

Roe, Brian, Alan S. Levy, and Brenda M. Derby (1999), "The Impact of Health Claims on Consumer Search and Product Evaluation Outcomes: Results from FDA Experimental Data," Journal of Public Policy \& Marketing, 18 (Spring), 89-105.

Rust, Roland T. and Bruce Cooil (1994), "Reliability Measures for Qualitative Data: Theory and Implications," Journal of Marketing Research, 31 (February), 1-14.

Seiders, Kathleen and Ross D. Petty (2004), "Obesity and the Role of Food Marketing: A Policy Analysis of Issues and Remedies," Journal of Public Policy \& Marketing, 23 (Fall), 153-69.

U.S. Bureau of the Census (2004), "Annual Estimates of the Population," (accessed January 20, 2009), [available at http://www. census.gov/popest/states/NST-ann-est.html].

Vakratsas, Demetrios and Tim Ambler (1999), "How Advertising Works: What Do We Really Know?" Journal of Marketing, 63 (January), 26-43.

Wang, Youfa and May A. Beydoun (2007), "The Obesity Epidemic in the United States: Gender, Age, Socioeconomic, Racial/Ethnic, and Geographical Characteristics: A Systematic Review and Meta-Regression Analysis," Epidemiological Reviews, 29 (May 17), 6-28.

Wansink, Brian (2005), Marketing Nutrition: Soy, Functional Foods, Biotechnology, and Obesity. Urbana: University of Illinois Press.

and Pierre Chandon (2006a), "Can 'Low-Fat' Nutrition Labels Lead to Obesity?" Journal of Marketing Research, 43 (November), 605-617.

— and (2006b), "Meal Size, Not Body Size, Explains Errors in Estimating the Calorie Content of Meals," Annals of Internal Medicine, 145 (5), 326-32.

and Mathew M. Cheney (2005), "Leveraging FDA Health Claims," Journal of Consumer Affairs, 39 (Winter), 386-97.

Zuckerman, Adam and Shelly Chaiken (1998), “A HeuristicSystematic Processing Analysis of the Effectiveness of Product Warning Labels," Psychology \& Marketing, 15 (7), 621-42. 